\title{
Calcium Signalling and Liver Regeneration
}

\author{
Isabelle Garcin $^{1,2}$ and Thierry Tordjmann ${ }^{1,2}$ \\ ${ }^{1}$ INSERM U.757, Université Paris Sud, Bât. 443, 91405 Orsay, France \\ ${ }^{2}$ Université Paris Sud, Bât. 443, 91405 Orsay, France \\ Correspondence should be addressed to Thierry Tordjmann, thierry.tordjmann@u-psud.fr
}

Received 29 June 2012; Accepted 12 September 2012

Academic Editor: Chantal Desdouets

Copyright (C 2012 I. Garcin and T. Tordjmann. This is an open access article distributed under the Creative Commons Attribution License, which permits unrestricted use, distribution, and reproduction in any medium, provided the original work is properly cited.

After partial hepatectomy $(\mathrm{PH})$ the initial mass of the organ is restored through a complex network of cellular interactions that orchestrate both proliferative and hepatoprotective signalling cascades. Among agonists involved in this network many of them drive $\mathrm{Ca}^{2+}$ movements. During liver regeneration in the rat, hepatocyte cytosolic $\mathrm{Ca}^{2+}$ signalling has been shown on the one hand to be deeply remodelled and on the other hand to enhance progression of hepatocytes through the cell cycle. Mechanisms through which cytosolic $\mathrm{Ca}^{2+}$ signals impact on hepatocyte cell cycle early after $\mathrm{PH}$ are not completely understood, but at least they include regulation of immediate early gene transcription and ERK and CREB phosphorylation. In addition to cytosolic $\mathrm{Ca}^{2+}$, there is also evidence that mitochondrial $\mathrm{Ca}^{2+}$ and also nuclear $\mathrm{Ca}^{2+}$ may be critical for the regulation of liver regeneration. Finally, $\mathrm{Ca}^{2+}$ movements in hepatocytes, and possibly in other liver cells, not only impact hepatocyte progression in the cell cycle but more generally may regulate cellular homeostasis after $\mathrm{PH}$.

\section{Introduction}

After partial hepatic destruction in experimental or clinical context, the initial mass of the organ is restored through compensatory growth of the remnant liver. A complex and yet incompletely elucidated network of cellular interactions (including paracrine, autocrine, endocrine, or nervous pathways) orchestrates the regulation of regeneration, through both proliferative and hepatoprotective signalling cascades [1]. A number of agonists constituting this network drive intracellular $\mathrm{Ca}^{2+}$ movements, in particular through the formation of inositol 1,4,5 trisphosphate which binds on its receptor in the membrane of the endoplasmic reticulum, and release the $\mathrm{Ca}^{2+}$ stored in this organelle. Such agonists include some of the main comitogenic - as noradrenalin [2], arginine vasopressin (AVP) [3], and adenosine triphosphate (ATP) [4] -and mitogenic factors, as epidermal growth factor (EGF), hepatocyte growth factor (HGF) [5], and insulin [6]. The resulting increase in ionized cytosolic calcium concentration generally consists of a regular succession of $\mathrm{Ca}^{2+}$ peaks (oscillations) [7] that can be transmitted to other cells (intercellular calcium waves) which mechanisms and functions are not fully known $[8,9]$. The impact of calcium signalling on liver regeneration has, however, only been scarcely studied.

\section{Hepatocyte $\mathrm{Ca}^{2+}$ Signalling: Mechanisms and Functions}

The first calcium oscillations were reported in hepatocytes [10], and numerous studies, both experimental and theoretical, have been conducted after that to decipher, in the hepatocyte, the machinery by which agonists generated cytosolic calcium signals. However, the functions of hepatocyte calcium signalling remain far less understood.

In hepatocytes, as in most nonexcitable cells, $\mathrm{Ca}^{2+}$ oscillations originate from the periodic opening of $\mathrm{Ca}^{2+}$ channels located in the ER membrane, following activation of the phosphoinositide cascade. The binding of an agonist to a membrane-bound receptor activates the $\mathrm{G} \alpha$-subunit of a G-protein complex coupled to the receptor. This activated G protein in turn stimulates phospholipase C (PLC) activity. The latter enzyme catalyzes the hydrolysis of the membranebound phosphatidyl-inositol bisphosphate $\left(\mathrm{PIP}_{2}\right)$ into diacyl -glycerol and inositol trisphosphate $\left(\mathrm{InsP}_{3}\right) . \mathrm{Ca}^{2+}$ release 
from the internal stores is ensured by the $\operatorname{Ins}_{3} \mathrm{R}$, an homotetramer that can bind up to $4 \mathrm{InsP}_{3}$ molecules, forming a $\mathrm{Ca}^{2+}$ channel which equilibrium open probability presents a bell-shaped dependence on cytosolic $\mathrm{Ca}^{2+}$ [11]. The decrease of $\left[\mathrm{Ca}^{2+}\right]_{\mathrm{i}}$ in the cytosol is due to the activity of the $\mathrm{Ca}^{2+}$ ATPases (SERCA pumps), which actively transports $\mathrm{Ca}^{2+}$ from the cytosol into the ER. $\mathrm{Ca}^{2+}$-regulated $\mathrm{InsP}_{3} \mathrm{Rs}$ and $\mathrm{Ca}^{2+}$ ATPases are together sufficient to generate $\mathrm{Ca}^{2+}$ oscillations [12]. In most cases, hormone-induced $\mathrm{Ca}^{2+}$ oscillations in hepatocytes take the form of repetitive, sharp spikes sometimes preceded by a slower, pacemaker-like elevation in the cytosolic $\mathrm{Ca}^{2+}$ concentration. These periodic increases in the level of free $\mathrm{Ca}^{2+}$ in the cytosol from about $0.1 \mu \mathrm{M}$ up to $1 \mu \mathrm{M}$ have been observed in hepatocytes in response to stimulation by a large number of agonists such as noradrenalin, vasopressin, phenylephrin, angiotensin II, adenosine triphosphate (ATP), histamine, and thrombin, the shape of the oscillations being agonist dependent [7]. The oscillation frequency increases with the agonist concentration, a phenomenon known as "frequency encoding", and is affected by external $\left[\mathrm{Ca}^{2+}\right]$ - and thus by the rate of $\mathrm{Ca}^{2+}$ entry into the cell through plasma membrane $\mathrm{Ca}^{2+}$ channels. Intracellular $\mathrm{Ca}^{2+}$ waves do not result from a simple diffusion of $\mathrm{Ca}^{2+}$ itself-which is quickly buffered-but from the spreading of $\mathrm{Ins}_{3}$ - which is more soluble in the cytosolthat mobilizes $\mathrm{Ca}^{2+}$ from storage compartments throughout the cell. A particular spatial pattern of subcellular $\operatorname{Ins}_{3} \mathrm{R}$ distribution was reported to support the direction of intracellular $\mathrm{Ca}^{2+}$ waves, starting from the canalicular region containing the most abundant and affine $\mathrm{Ins}_{3} \mathrm{R}$ isoform (type II Ins $\mathrm{P}_{3} \mathrm{R}$ ) and spreading toward the other regions of the cytosol, less sensitive to $\mathrm{InsP}_{3}$ [13]. As in many other cell types, intracellular movements of $\mathrm{Ca}^{2+}$ in hepatocytes, induced by hormones and neurotransmitters, may be propagated from cell to cell. Our group demonstrated in multicellular rat hepatocyte systems (couplets and triplets) that agonists such as vasopressin or noradrenalin induce tightly coordinated and sequentially ordered intracellular $\mathrm{Ca}^{2+}$ increases [8, 14-16]. Such signals were also observed in the intact perfused liver in which vasopressin elicits waves of $\left[\mathrm{Ca}^{2+}\right]_{\mathrm{i}}$ increase running along hepatocyte plates across the lobules [17-19]. We demonstrated that unidirectional $\mathrm{Ca}^{2+}$ waves resulted from a gradually decreasing cellular sensitivity to hormonal stimuli from the first to the last responding cell, and that this cell to cell heterogeneity was due to a lobular gradual distribution of hormonal receptors density [8]. Moreover, $\mathrm{InsP}_{3}$ has been shown to flow through gap junctions and thereby coordinate $\mathrm{Ca}^{2+}$ spiking among adjacent hepatocytes [20]. Such a configuration in which the most responsive hepatocytes drive the response of the less sensitive cells is similar to the cell to cell triggering of cardiac pacemaker cells $[8,21,22]$.

In general terms, $\mathrm{Ca}^{2+}$ oscillations in hepatocytes optimize the effect of hormonal stimulation, thanks to enzymes decoding [23] their frequency [24, 25], as proposed for glycogen metabolism in hepatocytes [26]. Since the early data showing that production of glucose by the liver was at least in part mediated by hormone-induced intracellular $\mathrm{Ca}^{2+}$ increases [27], most recent studies have deciphered the molecular mechanisms linking intracellular $\mathrm{Ca}^{2+}$ to glucose metabolism in hepatocytes [28-30]. In particular, the serinethreonine kinase "calcium calmodulin-dependent kinase II" (CaMKII), a major mediator of $\mathrm{Ca}^{2+}$ signalling in different cell types, has been found to play essential roles in the regulation of glycogenolysis and gluconeogenesis in hepatocytes, not only during physiological fasting, but also in the pathophysiological setting of obesity [28, 30]. It is moreover well established that $\mathrm{Ca}^{2+}$ oscillations in hepatocytes coordinate intramitochondrial ATP synthesis with cellular energy demand, maintaining cell homeostasis and viability [31]. It has also been demonstrated that [32] the temporal pattern of calcium signals was of major impact as to the expression of transcription factors in lymphocytes, but this aspect has never been investigated in hepatocytes. Many events related to bile secretion are also regulated by cytosolic $\mathrm{Ca}^{2+}$, such as vesicular trafficking and canalicular exocytosis of bile acid transporters [33, 34], permeability of tight junctions [35], or canalicular contraction $[9,36]$. Intracellular calcium waves, as described above, starting from the canaliculus to the basolateral poles may have physiological impact on secretion, as it has been shown in pancreatic acinar cells [37], although direct evidence in hepatocytes is lacking. Moreover, interhepatocyte calcium waves have been reported to support canalicular peristaltism and thereby to regulate bile flow, in the normal and regenerating rat liver $[3,38]$. As emphasized in the following, all these $\mathrm{Ca}^{2+}$-regulated physiological processes may impact the course of liver regeneration.

\section{Intracellular Calcium and Hepatocyte Proliferation: Liver Regeneration}

It is well established that intracellular $\mathrm{Ca}^{2+}$ is crucial for tissue homeostasis through regulation of cell cycle and apoptosis [7]. In particular, intracellular calcium has been reported to regulate cell proliferation at multiple steps of the cell cycle, from immediate early genes activation, toward G1-S and G2-M transitions, as well as during mitosis [39]. Pioneer studies have shown that extracellular calcium was crucial for liver regeneration [40]. Also, modifications of intracellular calcium homeostasis during liver regeneration have been reported, concerning $\mathrm{Ca}^{2+}$-binding proteins [41], membrane $\mathrm{Ca}^{2+}$-ATPases [42], or the $\mathrm{Ins}_{3}$ receptor $[43,44]$. It has been also suggested that the alteration of the $\mathrm{InsP}_{3}$ and $\mathrm{Ca}^{2+}$ mobilisation pathway could alter liver regeneration in the rat [45]. Subsequently, it has been shown in nonhepatocytic cell lines that the spatiotemporal organisation of $\mathrm{Ca}^{2+}$ signals was determined for the activation of transcription factors like CREB, NF- $\kappa \mathrm{B}$, or NF-AT, and for immediate early genes like c-fos or c-jun [46-48]. It is also well established that the activation of the RAS pathway is controlled by $\left[\mathrm{Ca}^{2+}\right]_{\mathrm{i}}$ oscillations [49]. Moreover, intra-nuclear calcium signals, which have been well documented [50], have a major impact on gene transcription [51-53] and can result either from the diffusion of cytosolic calcium to the nucleus, or from an Ins $\mathrm{P}_{3}$-mediated calcium release in the nucleus itself (see below) $[6,54]$. Finally, our previous work demonstrated that hepatocyte calcium signalling was deeply remodelled during 


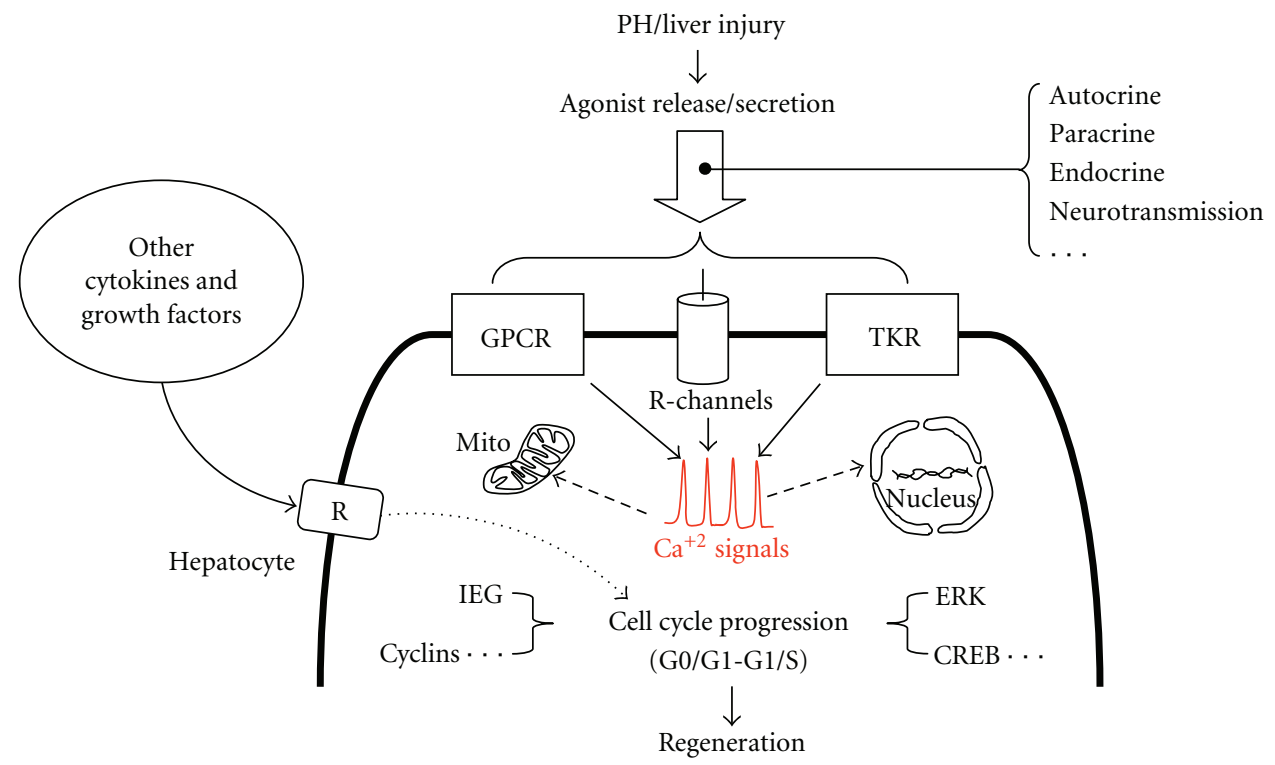

FIGURE 1: A simplified view of the impact of hepatocyte calcium signals during liver regeneration. After PH or toxic liver injury, a number of calcium mobilizing agonists are released inside or outside the liver, interacting with hepatocytes through autocrine, paracrine, and endocrine pathways. Diverse membrane receptors, either G protein coupled receptors (GPCR), tyrosine kinase receptors (TKR), or receptor channels (e.g., ionotropic purinergic receptors), can be involved in the generation of cytosolic calcium signals. These calcium movements in the cytosol can be transferred to other crucial compartments like the mitochondrion (Mito) or the nucleus, in which they could regulate respectively apoptosis and gene transcription. Previous studies have shown that cytosolic calcium signals regulate cell cycle progression from G0 to G1 and from $\mathrm{G} 1$ to $\mathrm{S}$ phases in hepatocytes after $\mathrm{PH}$, at least in part through an impact on immediate early genes transcription, cyclin expression, and ERK and CREB phosphorylation.

liver regeneration in the rat, contributing to the regulation of bile flow and cell proliferation $[3,55]$.

In a recent study, we examined the physiological involvement of cytosolic calcium during liver regeneration in the rat [56]. We interfered with calcium signalling before $\mathrm{PH}$ by expressing parvalbumin (PV) in the liver, a calcium-binding protein expressed in muscle cells and neurons but absent from the liver [57], using adenoviruses coding for PV targeted to the cytosol, to selectively buffer $\mathrm{Ca}^{2+}$ in this compartment $[53,54]$. We found that expression of PV efficiently buffers agonist-induced calcium oscillations in the cytosol and inhibits primary hepatocyte proliferation in vitro as well as in vivo during liver regeneration.

We found that immediate early gene transcription, early phosphorylation of ERK and CREB, and hepatocyte progression in the cell cycle after $\mathrm{PH}$ were inhibited in rats expressing cytosolic PV [56]. These data were in line with previous reports describing these pathways and genes as dependant on cytosolic and/or nuclear calcium signalling [46, 58$60]$. We thus suggested that attenuated $\left[\mathrm{Ca}^{2+}\right]_{\mathrm{i}}$ oscillations in calcium-buffered hepatocytes resulted in impaired activation of these pathways. A potential reduction in CaM-kinase activation, as previously reported [61], or reduced ERK1/2 activation that we observed in PV-NES expressing hepatocytes may have also contributed to altered CREB phosphorylation. Since CaM-kinase II [24], as well as ERK1/2 [60] activity, is sensitive to $\mathrm{Ca}^{2+}$ oscillation frequency, an attractive hypothesis would be that cytosolic PV expression, by attenuating agonist-generated $\mathrm{Ca}^{2+}$ signals, resulted in impaired phosphorylation of CREB.
Cytosolic calcium signalling impacts most likely the early triggering of hepatocyte progression from G0 to G1 and S phases. In line with this view, a rise in concentration-in the liver and in the plasma-is observed early after $\mathrm{PH}$ for several $\mathrm{Ca}^{2+}$-mobilizing agonists, suggesting these agonists might be involved in initiating the regeneration process. In particular, EGF and HGF elicit cytosolic $\mathrm{Ca}^{2+}$ oscillations in hepatocytes, the physiological impact of which has never been specifically addressed [5]. Also, extracellular ATP [4], arginine vasopressin [3], and noradrenalin [2], which are comitogenic $\mathrm{Ca}^{2+}$-mobilizing agonists, have been individually reported to contribute to early phases of liver regeneration. Our study thus suggested that buffering hepatocyte calcium signals, potentially generated by these agonists in the minutes after $\mathrm{PH}$, result in delaying hepatocyte cell cycle progression.

There is evidence in the literature for the crucial role of mitochondrial calcium in the regulation of apoptotic processes. It is well known in particular, that mitochondrial calcium overload can be one of the pathways leading to the swelling of mitochondria and to the rupture of the outer membrane, in turn releasing proapoptotic molecules in the cytosol. Mechanisms for excessive calcium transfer to mitochondria are debated and include mainly interactions between proteins of the $\mathrm{Bcl} 2$ family and the $\mathrm{InsP}_{3}-\mathrm{R}$. Antiapoptotic members appeared as reducing calcium transfer from the ER to the mitochondria, whereas proapoptotic factors were reported to enhance this flux [62]. In this context, recent data suggest that mitochondrial $\mathrm{Ca}^{2+}$, as well as cytosolic $\mathrm{Ca}^{2+}$, may be critical for the regulation of liver regeneration after $\mathrm{PH}$ in the rat [63]. The authors suggested 
that buffering calcium in the mitochondria resulted in a shift in the balance between pro- and antiapoptotic factors, thereby protecting hepatocytes from apoptosis, in vitro in an hepatoma cell line, as well as in vivo in the rat liver after $\mathrm{PH}$.

\section{Nuclear Calcium Signalling and Liver Cell Proliferation}

Previous studies have established that growth factors important for liver regeneration such as HGF [54] and insulin [6] can differentially affect cytosolic and nuclear calcium in hepatocytes. It has been reported that agonist-induced calcium movements in the nucleus can schematically result from the diffusion of cytosolic calcium to the nucleus and/or from an autonomous $\mathrm{Ins}_{3}$ generation and calcium mobilization from local, intra, or perinuclear $\mathrm{Ca}^{2+}$ stores $[64,65]$. Nuclear $\mathrm{InsP}_{3}$ may again come from the cytosol or be generated in the nucleus [6]. Indeed, the nucleus, its envelope and the nucleoplasmic reticulum, has been shown to possess several crucial molecules involved in $\mathrm{Ca}^{2+}$ storage, $\mathrm{Ins}_{3}$ production, and calcium release, therefore opening the possibility that local nuclear $\mathrm{Ca}^{2+}$ signals may occur independently from the cytosol $[64,65]$. Although these two views may coexist in the same cells according to circumstances and cell types, it has been shown in SkHep cells that an $\mathrm{InsP}_{3}$-sensitive intranuclear calcium compartment (i.e., the "nucleoplasmic reticulum") exists [50]. PLC $\beta, \mathrm{PIP}_{2}$, and $\mathrm{InsP}_{3} \mathrm{R}$ have been found in the nucleus, allowing a local $\mathrm{InsP}_{3}$ production and providing the machinery necessary to generate autonomous $\mathrm{Ca}^{2+}$ signals $[64,65]$. We also know that calcium signals in these two compartments-cytosol and nucleus-can have different effects $[51,58]$. Recent works revealed that buffering calcium in the nucleus, but not in the cytosol, in a hepatoma cell line, resulted in an inhibition of cell proliferation, suggesting that nuclear $\mathrm{Ca}^{2+}$ was necessary for centrosome separation and cell progression through early prophase [53]. Gomes et al. further showed that the HGF receptor (c-met) can translocate (upon agonist stimulation) from the plasma membrane to the nucleus and generate an $\mathrm{InsP}_{3}$ production and calcium elevation in the nucleus, independently of cytosolic calcium, in a hepatoma cell line [54]. Very similarly, it was shown by the same group that insulin can induce nuclear calcium signals through a translocation of its receptor to the nucleus, in primary rat hepatocytes [6]. Importantly, the nucleoplasmic reticulum as an intranuclear calcium compartment has not been shown in primary hepato-cytes, and some authors claimed that it was not essential for calcium signalling [66].

Important cellular functions are thought to be regulated by nuclear calcium signals, including nuclear pore permeability, transcription factor activity and protein kinase translocation, thereby controlling gene expression [65]. In particular, the transcriptional activity of CREB [58], NFAT [46], and DREAM [67] has been well described as dependent on nuclear $\mathrm{Ca}^{2+}$. Therefore, agonist-induced nuclear $\mathrm{Ca}^{2+}$ movements are potentially expected to impact both hepatocyte progression in the cell cycle and more generally cellular homeostasis after $\mathrm{PH}$.
It is important to realize that liver regeneration, seen as a process involving the whole organ-and even the entire organism-cannot be restrained to the sole hepatocyte division. In that view, after $\mathrm{PH}, \mathrm{Ca}^{2+}$ signalling may also regulate physiological processes unrelated directly to cell cycle control, although they may ultimately interfere with cell cycle progression, not only in hepatocytes but also in other liver cell types (cholangiocytes, endothelial and Kupffer cells). Whereas we do not have any direct data about the impact of $\mathrm{Ca}^{2+}$ signals in nonhepatocytic cells after $\mathrm{PH}$, we can easily anticipate about $\mathrm{Ca}^{2+}$-dependent physiological processes that may be crucial in hepatocytes after PH. For example, glucose homeostasis, which regulation is critical for hepatocyte exit from quiescence [68], may depend on $\mathrm{Ca}^{2+}$ signals early after PH. Also, biliary homeostasis, which adaptation after $\mathrm{PH}$ is critical for liver regeneration $[69,70]$, may involve $\mathrm{Ca}^{2+}$-dependent regulation $[3,71]$.

An integrated full picture of the "liver calcium signalling", which is obviously lacking, may improve our knowledge on the interaction network that regulates liver regeneration processes (Figure 1).

\section{References}

[1] R. Taub, "Liver regeneration: from myth to mechanism," Nature Reviews Molecular Cell Biology, vol. 5, no. 10, pp. 836847, 2004.

[2] J. L. Cruise, S. J. Muga, Y. S. Lee, and G. K. Michalopoulos, "Regulation of hepatocyte growth: Alpha-1 adrenergic receptor and ras p21 changes in liver regeneration," Journal of Cellular Physiology, vol. 140, no. 2, pp. 195-201, 1989.

[3] A. Nicou, V. Serriere, S. Prigent et al., "Hypothalamic vasopressin release and hepatocyte $\mathrm{Ca}^{2+}$ signaling during liver regeneration: an interplay stimulating liver growth and bile flow," The FASEB Journal, vol. 17, pp. 1901-1903, 2003.

[4] E. Gonzales, B. Julien, V. Serrière-Lanneau et al., "ATP release after partial hepatectomy regulates liver regeneration in the rat," Journal of Hepatology, vol. 52, no. 1, pp. 54-62, 2010.

[5] T. Mine, I. Kojima, E. Ogata, and T. Nakamura, "Comparison of effects of HGF and EGF on cellular calcium in rat hepatocytes," Biochemical and Biophysical Research Communications, vol. 181, no. 3, pp. 1173-1180, 1991.

[6] M. A. Rodrigues, D. A. Gomes, V. A. Andrade, M. F. Leite, and M. H. Nathanson, "Insulin induces calcium signals in the nucleus of rat hepatocytes," Hepatology, vol. 48, no. 5, pp. 1621-1631, 2008.

[7] M. J. Berridge, M. D. Bootman, and H. L. Roderick, "Calcium signalling: dynamics, homeostasis and remodelling," Nature Reviews Molecular Cell Biology, vol. 4, no. 7, pp. 517-529, 2003.

[8] T. Tordjmann, B. Berthon, E. Jacquemin et al., "Receptororiented intercellular calcium waves evoked by vasopressin in rat hepatocytes," The EMBO Journal, vol. 17, no. 16, pp. 46954703, 1998.

[9] V. Serrière, D. Tran, N. Stelly et al., "Vasopressin-induced morphological changes in polarized rat hepatocyte multiplets: dual calcium-dependent effects," Cell Calcium, vol. 43, no. 1, pp. 95-104, 2008.

[10] N. M. Woods and K. S. R. Cuthbertson, "Repetitive transient rises in cytoplasmic free calcium in hormone-stimulated hepatocytes," Nature, vol. 319, no. 6054, pp. 600-602, 1986. 
[11] C. W. Taylor, "Inositol trisphosphate receptors: $\mathrm{Ca}^{2+}$-modulated intracellular $\mathrm{Ca}^{2+}$ channels," Biochimica et Biophysica Acta, vol. 1436, no. 1-2, pp. 19-33, 1998.

[12] G. Dupont, S. Swillens, C. Clair, T. Tordjmann, and L. Combettes, "Hierarchical organization of calcium signals in hepatocytes: From experiments to models," Biochimica et Biophysica Acta, vol. 1498, no. 2-3, pp. 134-152, 2000.

[13] E. Hernandez, M. F. Leite, M. T. Guerra et al., "The spatial distribution of inositol 1,4,5-trisphosphate receptor isoforms shapes $\mathrm{Ca}^{2+}$ waves," Journal of Biological Chemistry, vol. 282, no. 13, pp. 10057-10067, 2007.

[14] M. H. Nathanson and A. D. Burgstahler, "Coordination of hormone-induced calcium signals in isolated rat hepatocyte couplets: demonstration with confocal microscopy," Molecular Biology of the Cell, vol. 3, no. 1, pp. 113-121, 1992.

[15] L. Combettes, D. Tran, T. Tordjmann, M. Laurent, B. Berthon, and M. Claret, " $\mathrm{Ca}^{2+}$-mobilizing hormones induce sequentially ordered $\mathrm{Ca}^{2+}$ signals in multicellular systems of rat hepatocytes," Biochemical Journal, vol. 304, part 2, pp. 585$594,1994$.

[16] T. Tordjmann, B. Berthon, M. Claret, and L. Combettes, "Coordinated intercellular calcium waves induced by noradrenaline in rat hepatocytes: dual control by gap junction permeability and agonist," The EMBO Journal, vol. 16, no. 17, pp. 5398-5407, 1997.

[17] M. H. Nathanson, A. D. Burgstahler, A. Mennone, M. B. Fallon, C. B. Gonzalez, and J. C. Saez, "Ca ${ }^{2+}$ waves are organized among hepatocytes in the intact organ," American Journal of Physiology-Gastrointestinal and Liver Physiology, vol. 269, no. 1, pp. G167-G171, 1995.

[18] L. D. Robb-Gaspers and A. P. Thomas, "Coordination of $\mathrm{Ca}^{2+}$ signaling by intercellular propagation of $\mathrm{Ca}^{2+}$ waves in the intact liver," Journal of Biological Chemistry, vol. 270, no. 14, pp. 8102-8107, 1995.

[19] S. Patel, L. D. Robb-Gaspers, K. A. Stellato, M. Shon, and A. P. Thomas, "Coordination of calcium signalling by endothelialderived nitric oxide in the intact liver," Nature Cell Biology, vol. 1, no. 8, pp. 467-471, 1999.

[20] C. Clair, C. Chalumeau, T. Tordjmann et al., "Investigation of the roles of $\mathrm{Ca}^{2+}$ and InsP3 diffusion in the coordination of $\mathrm{Ca}^{2+}$ signals between connected hepatocytes," Journal of Cell Science, vol. 114, part 11, pp. 1999-2007, 2001.

[21] G. Dupont, T. Tordjmann, C. Clair, S. Swillens, M. Claret, and L. Combettes, "Mechanism of receptor-oriented intercellular calcium wave propagation in hepatocytes," The FASEB Journal, vol. 14, no. 2, pp. 279-289, 2000.

[22] M. F. Leite, K. Hirata, T. Pusl et al., "Molecular basis for pacemaker cells in epithelia," Journal of Biological Chemistry, vol. 277, no. 18, pp. 16313-16323, 2002.

[23] T. Meyer and L. Stryer, "Calcium spiking," Annual Review of Biophysics and Biophysical Chemistry, vol. 20, pp. 153-174, 1991.

[24] P. de Koninck and H. Schulman, "Sensitivity of CaM kinase II to the frequency of $\mathrm{Ca}^{2+}$ oscillations," Science, vol. 279, no. 5348, pp. 227-230, 1998.

[25] P. I. Hanson, T. Meyer, L. Stryer, and H. Schulman, "Dual role of calmodulin in autophosphorylation of multifunctional CaM kinase may underlie decoding of calcium signals," Neuron, vol. 12, no. 5, pp. 943-956, 1994.

[26] D. Gall, E. Baus, and G. Dupont, "Activation of the liver glycogen phosphorylase by $\mathrm{Ca}^{2+}$ oscillations: a theoretical study," Journal of Theoretical Biology, vol. 207, no. 4, pp. 445454,2000 .
[27] J. H. Exton, "Mechanisms of hormonal regulation of hepatic glucose metabolism," Diabetes/Metabolism Reviews, vol. 3, no. 1, pp. 163-183, 1987.

[28] L. Ozcan, C. C. Wong, G. Li et al., "Calcium signaling through CaMKII regulates hepatic glucose production in fasting and obesity," Cell Metabolism, vol. 15, no. 5, pp. 739-751, 2012.

[29] Y. Wang, G. Li, J. Goode et al., "Inositol-1, 4, 5-trisphosphate receptor regulates hepatic gluconeogenesis in fasting and diabetes," Nature, vol. 485, no. 7396, pp. 128-132, 2012.

[30] K. A. Anderson, F. Lin, T. J. Ribar et al., "Deletion of CaMKK2 from the liver lowers blood glucose and improves whole-body glucose tolerance in the mouse," Molecular Endocrinology, vol. 26, no. 2, pp. 281-291, 2012.

[31] L. D. Robb-Gaspers, G. A. Rutter, P. Burnett, G. Hajnóczky, R. M. Denton, and A. P. Thomas, "Coupling between cytosolic and mitochondrial calcium oscillations: role in the regulation of hepatic metabolism," Biochimica et Biophysica Acta, vol. 1366, no. 1-2, pp. 17-32, 1998.

[32] R. E. Dolmetsch, K. Xu, and R. S. Lewis, "Calcium oscillations increase the efficiency and specificity of gene expression," Nature, vol. 392, no. 6679, pp. 933-936, 1998.

[33] U. Beuers, M. H. Nathanson, C. M. Isales, and J. L. Boyer, "Tauroursodeoxycholic acid stimulates hepatocellular exocytosis and mobilizes extracellular $\mathrm{Ca}++$ mechanisms defective in cholestasis," Journal of Clinical Investigation, vol. 92, no. 6, pp. 2984-2993, 1993.

[34] U. Beuers, M. Bilzer, A. Chittattu et al., "Tauroursodeoxycholic acid inserts the apical conjugate export pump, Mrp2, into canalicular membranes and stimulates organic anion secretion by protein kinase C-dependent mechanisms in cholestatic rat liver," Hepatology, vol. 33, no. 5, pp. 1206-1216, 2001.

[35] M. H. Nathanson, A. Gautam, O. C. Ng, R. Bruck, and J. L. Boyer, "Hormonal regulation of paracellular permeability in isolated rat hepatocyte couplets," American Journal of Physiology —Gastrointestinal and Liver Physiology, vol. 262, no. 6, pp. G1079-G1086, 1992.

[36] T. Kitamura, U. Brauneis, Z. Gatmaitan, and I. M. Arias, "Extracellular ATP, intracellular calcium and canalicular contraction in rat hepatocyte doublets," Hepatology, vol. 14, no. 4, pp. 640-647, 1991.

[37] K. Ito, Y. Miyashita, and H. Kasai, "Micromolar and submicromolar $\mathrm{Ca}^{2+}$ spikes regulating distinct cellular functions in pancreatic acinar cells," The EMBO Journal, vol. 16, no. 2, pp. 242-251, 1997.

[38] V. Serrière, B. Berthon, S. Boucherie et al., "Vasopressin receptor distribution in the liver controls calcium wave propagation and bile flow," The FASEB Journal, vol. 15, no. 8, pp. 1484-1486, 2001.

[39] C. R. Kahl and A. R. Means, "Regulation of cell cycle progression by calcium/calmodulin-dependent pathways," Endocrine Reviews, vol. 24, no. 6, pp. 719-736, 2003.

[40] J. F. Whitfield, A. L. Boynton, J. P. MacManus et al., "The roles of calcium and cyclic AMP in cell proliferation," Annals of the New York Academy of Sciences, vol. 339, pp. 216-240, 1980.

[41] T. Katsumata and M. Yamaguchi, "Inhibitory effect of calcium-binding protein regucalcin on protein kinase activity in the nuclei of regenerating rat liver," Journal of Cellular Biochemistry, vol. 71, pp. 569-576, 1998.

[42] H. Takahasi and M. Yamaguchi, "Enhancement of plasma membrane $\left(\mathrm{Ca}^{2+}-\mathrm{Mg}^{2+}\right)$-ATPase activity in regenerating rat liver: involvement of endogenous activating protein regucalcin," Molecular and Cellular Biochemistry, vol. 162, no. 2, pp. 133-138, 1996. 
[43] M. Diaz-Munoz, R. Canedo-Merino, J. Gutierrez-Salinas, and R. Hernandez-Munoz, "Modifications of intracellular calcium release channels and calcium mobilization following 70\% hepatectomy," Archives of Biochemistry and Biophysics, vol. 349, pp. 105-112, 1998.

[44] F. Magnino, M. St-Pierre, M. Lüthi, M. Hilly, J. P. Mauger, and J. F. Dufour, "Expression of intracellular calcium channels and pumps after partial hepatectomy in rat," Molecular Cell Biology Research Communications, vol. 3, no. 6, pp. 374-379, 2000.

[45] B. H. Zhang, B. P. Horsfield, and G. C. Farrell, "Chronic ethanol administration to rats decreases receptor-operated mobilization of intracellular ionic calcium in cultured hepatocytes and inhibits 1,4,5-inositol trisphosphate production: relevance to impaired liver regeneration," Journal of Clinical Investigation, vol. 98, no. 5, pp. 1237-1244, 1996.

[46] R. E. Dolmetsch, R. S. Lewis, C. C. Goodnow, and J. I. Healy, "Differential activation of transcription factors induced by $\mathrm{Ca}^{2+}$ response amplitude and duration," Nature, vol. 386, no. 6627, pp. 855-858, 1997.

[47] I. A. Graef, P. G. Mermelstein, K. Stankunas et al., "L-type calcium channels and GSK-3 regulate the activity of NF-ATc4 in hippocampal neurons," Nature, vol. 401, no. 6754, pp. 703708, 1999.

[48] V. Sée, N. K. M. Rajala, D. G. Spiller, and M. R. H. White, "Calcium-dependent regulation of the cell cycle via a novel MAPK-NF- $\kappa$ B pathway in Swiss 3T3 cells," Journal of Cell Biology, vol. 166, no. 5, pp. 661-672, 2004.

[49] P. J. Cullen and P. J. Lockyer, "Integration of calcium and Ras signalling," Nature Reviews Molecular Cell Biology, vol. 3, no. 5, pp. 339-348, 2002.

[50] W. Echevarria, M. F. Leite, M. T. Guerra, W. R. Zipfel, and M. H. Nathanson, "Regulation of calcium signals in the nucleus by a nucleoplasmic reticulum," Nature Cell Biology, vol. 5, no. 5, pp. 440-446, 2003.

[51] T. Pusl, J. J. Wu, T. L. Zimmerman et al., "Epidermal growth factor-mediated activation of the ETS domain transcription factor Elk-1 requires nuclear calcium," Journal of Biological Chemistry, vol. 277, no. 30, pp. 27517-27527, 2002.

[52] R. Dolmetsch, "Excitation-transcription coupling: signaling by ion channels to the nucleus," Science's STKE, vol. 2003, no. 166, p. PE4, 2003.

[53] M. A. Rodrigues, D. A. Gomes, M. F. Leite et al., "Nucleoplasmic calcium is required for cell proliferation," Journal of Biological Chemistry, vol. 282, no. 23, pp. 17061-17068, 2007.

[54] D. A. Gomes, M. A. Rodrigues, M. F. Leite et al., "c-Met must translocate to the nucleus to initiate calcium signals," Journal of Biological Chemistry, vol. 283, no. 7, pp. 4344-4351, 2008.

[55] A. Nicou, V. Serrière, M. Hilly et al., "Remodelling of calcium signalling during liver regeneration in the rat," Journal of Hepatology, vol. 46, no. 2, pp. 247-256, 2007.

[56] L. Lagoudakis, I. Garcin, B. Julien et al., "Cytosolic calcium regulates liver regeneration in the rat," Hepatology, vol. 52, no. 2, pp. 602-611, 2010.

[57] T. L. Pauls, J. A. Cox, and M. W. Berchtold, "The $\mathrm{Ca}^{2+}$-binding proteins parvalbumin and oncomodulin and their genes: new structural and functional findings," Biochimica et Biophysica Acta, vol. 1306, no. 1, pp. 39-54, 1996.

[58] G. E. Hardingham, S. Chawla, C. M. Johnson, and H. Bading, "Distinct functions of nuclear and cytoplasmic calcium in the control of gene expression," Nature, vol. 385, no. 6613, pp. 260-265, 1997.

[59] K. Deisseroth and R. W. Tsien, "Dynamic multiphosphorylation passwords for activity-dependent gene expression," Neuron, vol. 34, no. 2, pp. 179-182, 2002.
[60] S. Kupzig, D. Deaconescu, D. Bouyoucef et al., "GAP1 family members constitute bifunctional Ras and Rap GTPaseactivating proteins," Journal of Biological Chemistry, vol. 281, no. 15, pp. 9891-9900, 2006.

[61] J. M. Kornhauser, C. W. Cowan, A. J. Shaywitz et al., "CREB transcriptional activity in neurons is regulated by multiple, calcium-specific phosphorylation events," Neuron, vol. 34, no. 2, pp. 221-233, 2002.

[62] C. Giorgi, F. Baldassari, A. Bononi et al., "Mitochondrial $\mathrm{Ca}^{+}$ and apoptosis," Cell Calcium, vol. 52, pp. 36-43, 2012.

[63] M. T. Guerra, E. A. Fonseca, F. M. Melo et al., "Mitochondrial calcium regulates rat liver regeneration through the modulation of apoptosis," Hepatology, vol. 54, no. 1, pp. 296-306, 2011.

[64] J. P. Mauger, "Role of the nuclear envelope in calcium signalling," Biology of the Cell, vol. 104, no. 2, pp. 70-83, 2012.

[65] D. A. Gomes, M. F. Leite, A. M. Bennett, and M. H. Nathanson, "Calcium signaling in the nucleus," Canadian Journal of Physiology and Pharmacology, vol. 84, no. 3-4, pp. 325-332, 2006.

[66] S. Bezin, P. Fossier, and J. M. Cancela, "Nucleoplasmic reticulum is not essential in nuclear calcium signalling mediated by cyclic ADPribose in primary neurons," Pflugers Archiv European Journal of Physiology, vol. 456, no. 3, pp. 581-586, 2008.

[67] A. M. Carrión, W. A. Link, F. Ledo, B. Mellström, and J. R. Naranjo, "DREAM is a $\mathrm{Ca}^{2+}$-regulated transcriptional repressor," Nature, vol. 398, no. 6722, pp. 80-84, 1999.

[68] A. Weymann, E. Hartman, V. Gazit et al., "P21 is required for dextrose-mediated inhibition of mouse liver regeneration," Hepatology, vol. 50, no. 1, pp. 207-215, 2009.

[69] W. Huang, K. Ma, J. Zhang et al., "Nuclear receptor-dependent bile acid signaling is required for normal liver regeneration," Science, vol. 312, no. 5771, pp. 233-236, 2006.

[70] I. L. Csanaky, L. M. Aleksunes, Y. Tanaka, and C. D. Klaassen, "Role of hepatic transporters in prevention of bile acid toxicity after partial hepatectomy in mice," American Journal of Physiology - Gastrointestinal and Liver Physiology, vol. 297, no. 3, pp. G419-G433, 2009.

[71] L. N. Cruz, M. T. Guerra, E. Kruglov et al., "Regulation of multidrug resistance-associated protein 2 by calcium signaling in mouse liver," Hepatology, vol. 52, no. 1, pp. 327-337, 2010. 


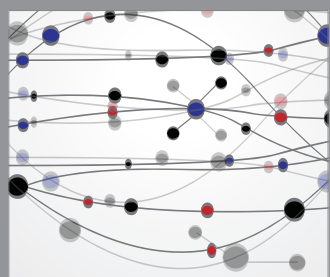

The Scientific World Journal
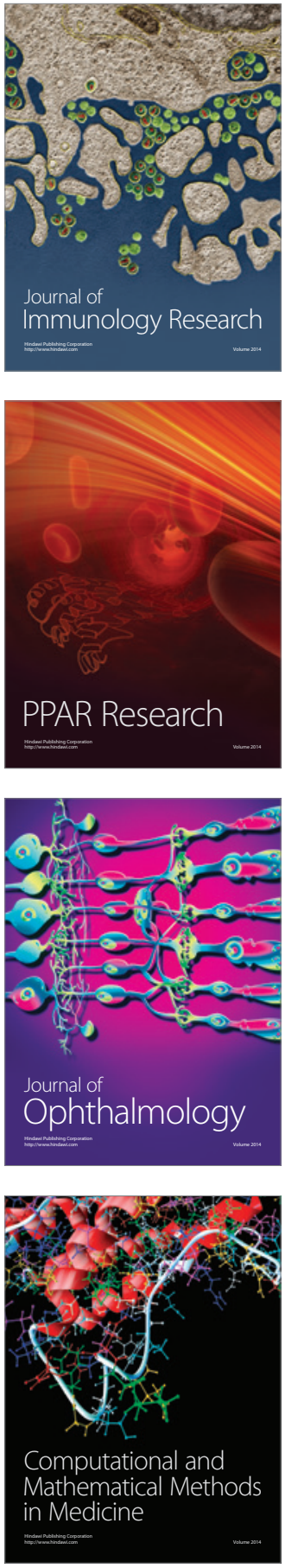

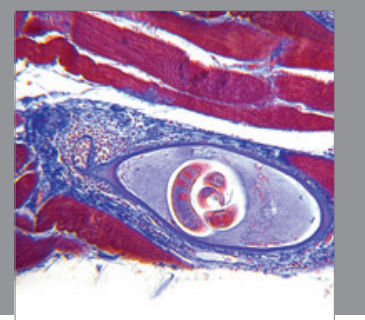

Gastroenterology

Research and Practice
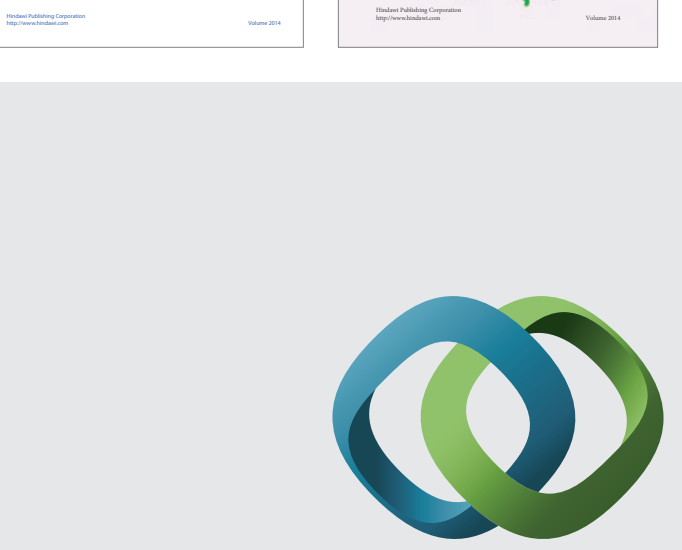

\section{Hindawi}

Submit your manuscripts at

http://www.hindawi.com
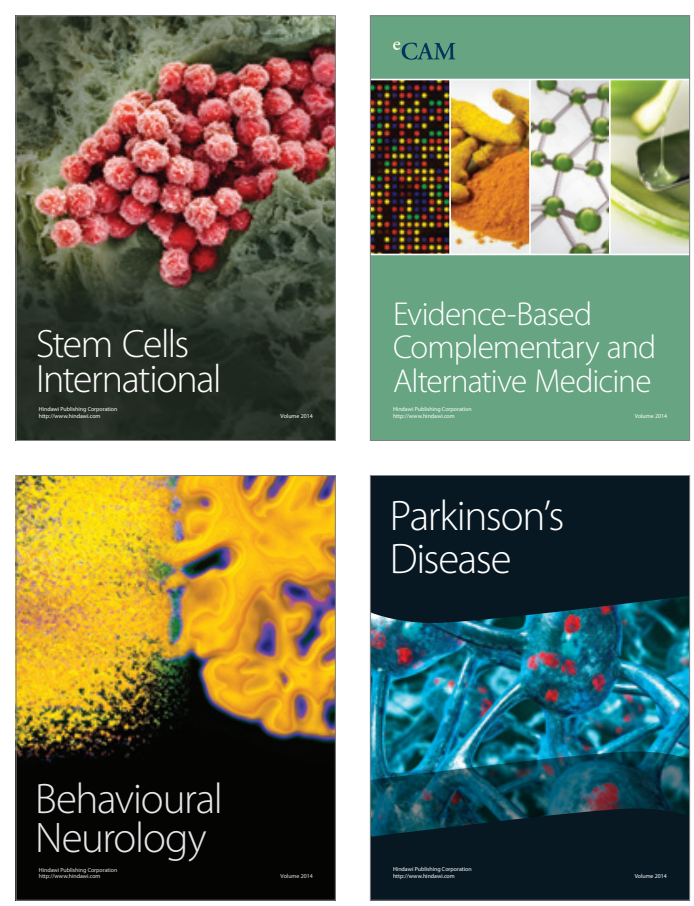

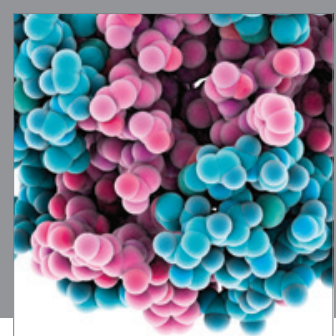

Journal of
Diabetes Research

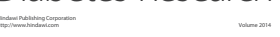

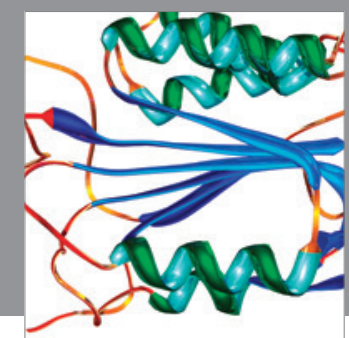

Disease Markers
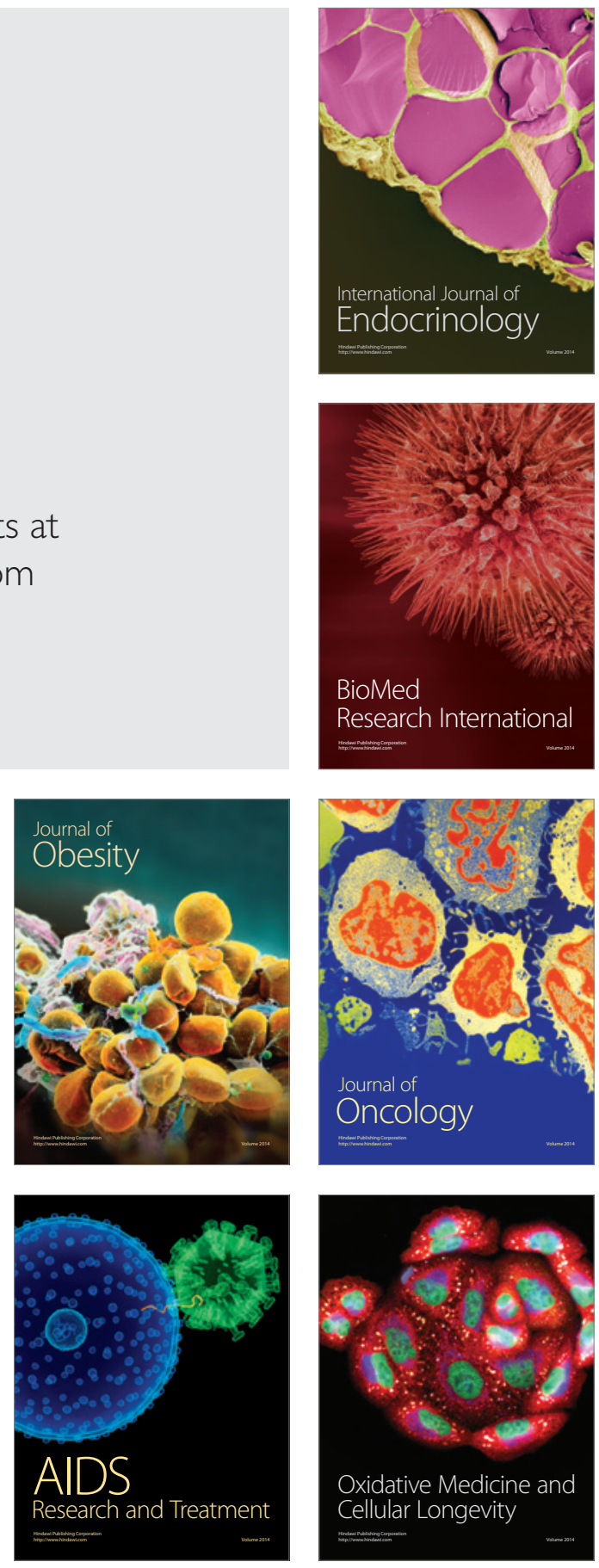